\title{
Reply to Comment on \\ "Global structure, seasonal and interannual variability of the migrating semidiurnal tide seen in the SABER/TIMED temperatures (2002-2007)" by Manson et al. (2010)
}

\author{
D. Pancheva, P. Mukhtarov, and B. Andonov \\ Geophysical Institute, Bulgarian Academy of Sciences, Sofia, Bulgaria
}

Received: 16 November 2009 - Revised: 3 February 2010 - Accepted: 19 February 2010 - Published: 25 February 2010

\section{Introduction}

In order to avoid some confusions it is important to clarify that the presented below reply is to the original Manson et al. (2009, hereafter referred to as METAL09) comment on our paper, Pancheva et al. (2009a, hereafter referred to as PETAL09). The two parts added later in METAL09 and related to: (i) their warning about "the vertical phase-gradient [degrees per $\mathrm{km}$ ] and that conversion of this number into a vertical wavelength can be problematic when the height interval used is smaller than the calculated wavelength", and (ii) the comparison between the MF and meteor radar wind measurements, are the authors' reaction to our original Reply paper which is presented here.

In their original comment, METAL09 raised two important problems related to the comparison of the climatological features of the atmospheric waves, particularly semidiurnal tides, obtained by: (i) satellites and ground based equipments, and (ii) medium frequency (MF) and meteor radars. The first problem has been provoked by some comparisons made by PETAL09 between the migrating semidiurnal tide seen in SABER/TIMED temperatures and the semidiurnal tidal perturbations derived from $\mathrm{Na}$ lidar observations over Fort Collins, Colorado $\left(41^{\circ} \mathrm{N}, 105^{\circ} \mathrm{W}\right)$ reported by Yuan et al. (2008, hereafter referred as YETAL08). We note especially that in PETAL09 the term "migrating" was not used for the semidiurnal tidal characteristics reported by YETAL08. The comparison was done as an illustration of the considerable amount of work that has been done recently by the $\mathrm{Na}$ lidar observations on the semidiurnal tidal variations (She,

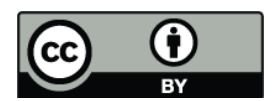

Correspondence to: D. Pancheva (dpancheva@geophys.bas.bg)
2004; She et al., 2002, 2003, 2004; YETAL09). In their comment METAL09 noted some seasonal differences in the tidal features, particularly summer vertical wavelength and September amplification of the tidal amplitude, obtained by satellite and Na lidar temperature measurements. We completely agree with METAL09 that providing both systems have adequate height and horizontal resolution, the observed tidal features should not be system dependent. The supportive evidence will be found below.

The second problem is related again with the September amplification of the tidal amplitude, but this time seen in the neutral winds measured by ground based radars. In order to support the importance of the September tidal maximum only the results of MF radar measurements are presented in METAL09. The difference between the MF and meteor radar measurements however have been well known for many years and widely described in the literature (see for example, Pancheva et al., 2002 and all references there). In our reply some additional comments on this issue will be added.

2 Comparison between the superposition of semidiurnal tides for a geographic point $\left(40^{\circ} \mathrm{N}, \mathbf{1 0 5}^{\circ} \mathrm{W}\right)$ seen in SABER/TIMED temperatures and the semidiurnal tidal perturbation defined by the Na lidar temperature observations over Fort Collins, Colorado $\left(41^{\circ} \mathrm{N}\right.$, $105^{\circ} \mathrm{W}$ )

In this section a detailed comparison between the climatological features of the semidiurnal oscillation seen in the SABER/TIMED temperatures at a point $\left(40^{\circ} \mathrm{N}, 105^{\circ} \mathrm{W}\right)$ and $\mathrm{Na}$ lidar observations over Fort Collins, Colorado $\left(41^{\circ} \mathrm{N}\right.$, $105^{\circ} \mathrm{W}$ ) will be presented.

Published by Copernicus Publications on behalf of the European Geosciences Union. 
The obvious advantage of the satellite-based atmospheric sampling is the global spatial coverage that is capable of being achieved, while for ground-based methods - their ability to distinguish various waves in the time domain, providing also their vertical structure but usually in a limited altitude range. Continuous measurements for SABER/TIMED are available for latitude and altitude ranges respectively $50^{\circ} \mathrm{N}-$ $50^{\circ} \mathrm{S}$ and $20-120 \mathrm{~km}$, while for the single point $\mathrm{Na}$ lidar measurements the altitude coverage is only between $\sim 80$ and $\sim 100 \mathrm{~km}$. A significant disadvantage of the satellite measurements is their inability to investigate short-term variability of various oscillations. Because of local time satellite precession TIMED needs 60 days in order all local times to be covered having in mind ascending and descending orbits. This means that the wave features can be obtained only by using a 60-day window. The lidar (as well as radar) measurements can characterize various frequencies of oscillations during a given period of time, but cannot resolve their zonal and latitude structure and sometimes can provide misleading information about the vertical wavelength because of the limited altitude coverage. It is important to note that it has proven impossible to determine unambiguously the tidal modes from the limited ground-based lidar or radar measurements. Therefore, in order to make a comparison between the semidiurnal tidal features determined by satellite and ground-based measurements at a fix geographic point we need first to calculate the superposition of all semidiurnal tides obtained by satellite data for the considered fix point and then to make a comparison with the ground-based semidiurnal features.

In the end of their comment METAL09 expressed some doubt about the possibility the data analysis method used in PETAL09 to provide: "an unbiased/non-aliased product". It is worth nothing that this method, described in detail by Pancheva et al. (2009b), is still the only method used until now where all tides (migrating and nonmigrating) and all planetary waves (stationary and zonally traveling) are extracted simultaneously from the satellite data. Because of widespread understanding about some limitation in getting tidal information from a slowly precessing satellite the above mentioned method was tested on numerous synthetic time series before to be used. The results from these tests as well as details for the tidal assessment, i.e. how to determine the reference noise level (because of satellite data sampling pattern and variability of the planetary waves in the 60-day window), were reported in Pancheva et al. (2009c). The similarity between the migrating tidal characteristics found by this method and other known in the literature methods described in Mukhtarov et al. (2009) and PETAL09, as well as between the planetary waves in the stratosphere seen in the SABER/TIMED and UK Met Office temperatures (Pancheva et al., 2009b) clearly supported the validity of this method. The detailed comparison between the features of the semidiurnal oscillation seen in the SABER/TIMED temperatures at a geographic point $\left(40^{\circ} \mathrm{N}, 105^{\circ} \mathrm{W}\right)$ and the $\mathrm{Na}$ lidar ob- servations over Fort Collins, Colorado $\left(41^{\circ} \mathrm{N}, 105^{\circ} \mathrm{W}\right)$ will provide once more evidence about the correctness of this method.

Before to present the above mentioned comparison we give some general information about the migrating and nonmigrating semidiurnal tides which are observed in the SABER/TIMED temperatures during 2002-2007. Figure 1 shows the average (2002-2007) altitude spectra of the tidal components at latitude of $40^{\circ} \mathrm{N}$; only those zonal wavenumbers are presented for which the nonmigrating semidiurnal components are well evident, i.e. westward propagating tides with $s=-1$ and $s=-3$ and eastward propagating one with $s=2$ and $s=3$ (we remind that only tides with zonal wavenumbers up to 4 are included in the decomposition procedure, Pancheva et al., 2009b). While the migrating semidiurnal average peak reaches magnitude of $14 \mathrm{~K}$, those of the nonmigrating peaks do not exceed 3-3.5 K. This result supports the statement made in METAL09 about the dominance of the migrating tide in comparison with all semidiurnal modes in the middle latitudes. However, the found in PETAL09 differences between the climatology of the SABER/TIMED migrating semidiurnal tide and the lidar semidiurnal oscillation, particularly summer vertical wavelength and September amplification of the lidar tidal amplitude, mean that the effect of the nonmigrating semidiurnal tides in composing the semidiurnal oscillation at a given midlatitude geographical point is not negligible.

Figure 2 presents the effect of SABER semidiurnal tidal superposition with respect to the migrating semidiurnal tide for geographic point $\left(40^{\circ} \mathrm{N}, 105^{\circ} \mathrm{W}\right)$, i.e. a point which is very close to the Na lidar observations at Fort Collins, Colorado $\left(41^{\circ} \mathrm{N}, 105^{\circ} \mathrm{W}\right)$. Figure $2 \mathrm{a}$ shows the altitude-time cross sections of the amplitudes in $\mathrm{K}$ (upper plot) and phases in degrees (bottom plot) of the migrating semidiurnal tide (noted as SW2). This is the same figure as the left plots of Fig. 2 from PETAL09, but with an extended altitude range, $50-120 \mathrm{~km}$, in order some seasonal features to be clearly distinguished. The SW2 thermal tide maximizes in the lower thermosphere, $\sim 110 \mathrm{~km}$ height, where the seasonal behavior is dominated by semiannual variability with solstice amplifications. While at $90 \mathrm{~km}$ height the winter maximum is seen below $85 \mathrm{~km}$ some equinoctial amplification can be noted. The seasonal variability of the SW2 vertical wavelength is well visible from the tidal phase plot. While in winter the vertical wavelength is $\sim 30-35 \mathrm{~km}$ in summer it reaches $\sim 50$ $60 \mathrm{~km}$. A similar seasonal variability of the SABER SW2 tide was found by Zhang et al. (2006); the authors demonstrated that the winter amplification near $90 \mathrm{~km}$ height is supported by the GSWM02 as well. Zhang et al. (2006) found similar to PETAL09 SW2 vertical wavelength only in winter, $\sim 34 \mathrm{~km}$; from their summer tidal phases a clear vertical wavelength cannot be determined. The above mentioned authors similarly to PETAL09 indicated the presence of highorder migrating modes generated by mode coupling, as $(2,5)$ and $(2,6)$. 
AVERAGE (2002-2007) AMPLITUDE SPECTRA
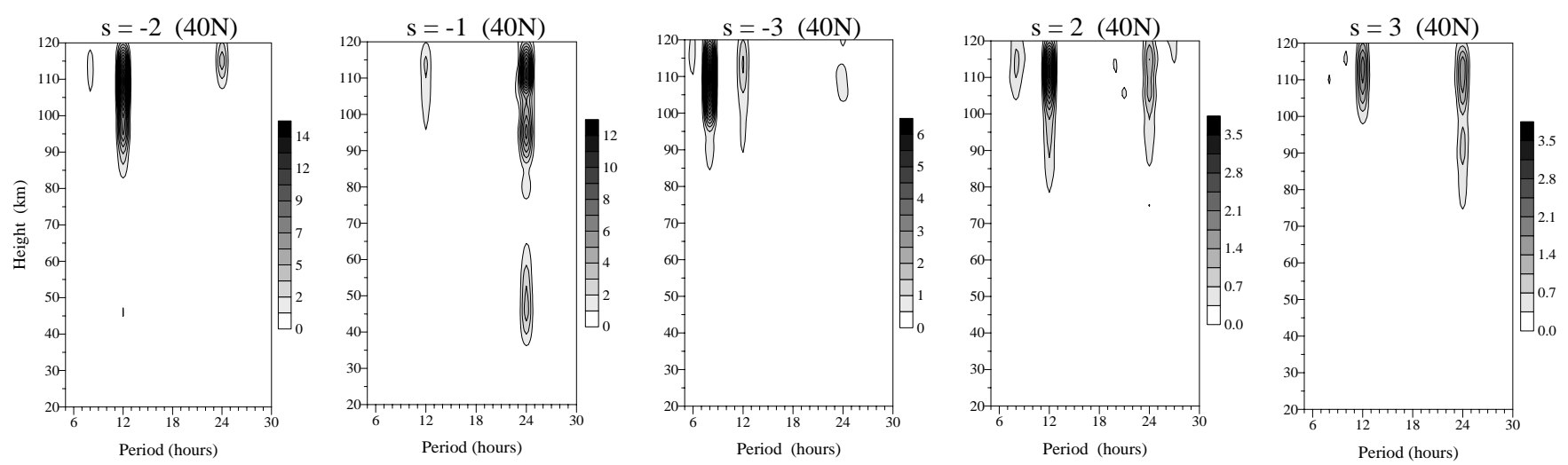

Fig. 1. Average (2002-2007) altitude spectra of the tidal components at latitude of $40^{\circ} \mathrm{N}$; only zonal wavenumbers for which the nonmigrating semidiurnal components are well evident are presented, i.e. westward propagating tides with $s=-1$ and $s=-3$ and eastward propagating one with $s=2$ and $s=3$.

Figure $2 b$ shows the altitude-time cross sections of the amplitudes (upper plot) and phases (bottom plot) of the superposition of all semidiurnal tides with zonal wavenumber up to 4 , observed at a geographic point $\left(40^{\circ} \mathrm{N}, 105^{\circ} \mathrm{W}\right)$. The effect of the superposition with respect to the SW2 tide can be summarized as follows: (i) the summer maximum increases ( $32 \mathrm{~K}$ from (b) in comparison of $26 \mathrm{~K}$ from (a)) while the winter one decreases in the lower thermosphere; (ii) for altitudes below $90 \mathrm{~km}$ the fall maximum increases ( $\sim 6 \mathrm{~K}$ from (b) in comparison of $\sim 4 \mathrm{~K}$ from (a)), and (iii) the phase distribution shows again vertical propagation of the semidiurnal oscillation, however the vertical phase gradient, particularly in summer, is too variable; there are altitude ranges where the phase almost does not change with altitude.

Figure 3 shows the average (2002-2007) vertical structures of the SW2 tide (a) and semidiurnal oscillation (b) at a geographic point $\left(40^{\circ} \mathrm{N}, 105^{\circ} \mathrm{W}\right)$. In this case in order to facilitate the comparison the vertical scales of the wave amplitudes are the same. From climatological point of view the superposition of semidiurnal tides with respect to the SW2 tide in middle latitudes leads to an amplification of summer (May-June) maximum and attenuation of the winter (January-December) one in the lower thermosphere and an amplification of the wave amplitudes during September-October in altitude range $80-90 \mathrm{~km}$. Therefore, the reason for the observed larger amplitudes of the semidiurnal tidal perturbation observed by the Na lidar in September (YETAL08) than those of the SABER SW2 tide (PETAL09) is due to the presence of nonmigrating semidiurnal modes. The effect of the tidal superposition on the phase distribution is larger in summer. While the vertical phase gradient below $75 \mathrm{~km}$ is similar to that in winter, it is very small between $75 \mathrm{~km}$ and $95-100 \mathrm{~km}$. Regardless of variable vertical phase gradients during winter and summer the average (2002-2007) vertical wavelengths of the semidiurnal oscil- lation in middle latitudes change again from $\sim 35-40 \mathrm{~km}$ in winter to $50-60 \mathrm{~km}$ in summer.

The variable vertical phase gradient however has serious impact on the ground-based lidar or radar results about the vertical wavelength of the observed semidiurnal perturbation. Usually the measurements of these instruments cover only a part of the vertical wavelength of the considered perturbation and the vertical wavelength is calculated from the vertical phase gradient. The Na lidar at Fort Collins, Colorado $\left(41^{\circ} \mathrm{N}, 105^{\circ} \mathrm{W}\right)$ covers an altitude range between $80 \mathrm{~km}$ and $100 \mathrm{~km}$. During winter, when the vertical phase gradient is almost the same at all heights the defined by the lidar vertical wavelength should be similar to that defined by the SABER superposition of semidiurnal tides at a geographic point $\left(40^{\circ} \mathrm{N}, 105^{\circ} \mathrm{W}\right)$. In summer however, when the altitude distribution of the vertical phase gradient is very different, the defined by the lidar and SABER vertical wavelengths should be different. Because the lidar data cover the altitude range $(80-100 \mathrm{~km})$ where the vertical phase gradient is very small, the lidar vertical wavelength should be larger than the SABER one. It has been mentioned above that below $75 \mathrm{~km}$ altitude the vertical phase gradient is similar to that in winter. This result supports the found short vertical wavelength of $\sim 35 \mathrm{~km}$ during summer and equinoxes below $\sim 80 \mathrm{~km}$ by some radar measurements mentioned in METAL09.

The seasonal course of the semidiurnal tidal perturbation reported by YETAL08 was obtained on the basis of Na lidar observations over full diurnal cycles from May 2002 to April 2006. For this purpose we calculated the seasonal vertical structure of the SABER amplitudes and phases (in LT) of the semidiurnal oscillation for a geographic point $\left(40^{\circ} \mathrm{N}\right.$, $105^{\circ} \mathrm{W}$ ) for the same period of time. Figure 4 presents the vertical phase profiles for typical winter (December), summer (June) and fall (September) months only for the same 
(a)

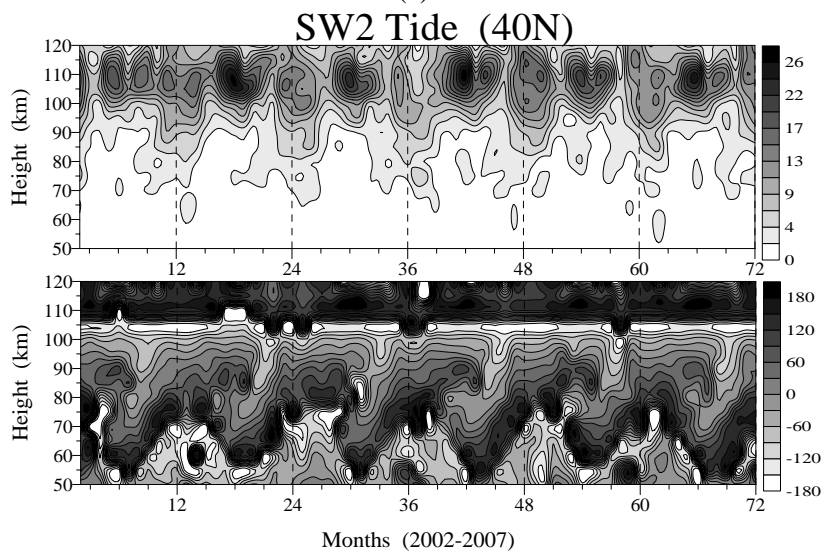

(b)

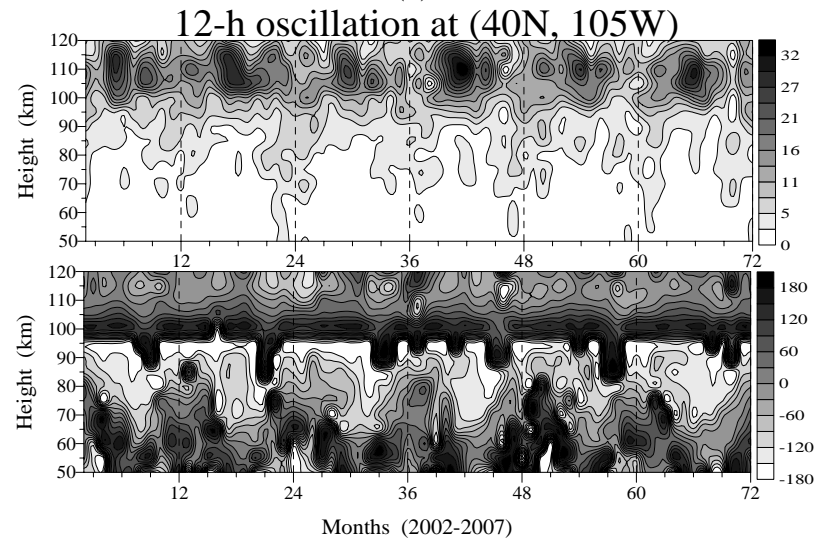

Fig. 2. (a) Altitude-time cross sections of the SABER SW2 tidal amplitudes in Kelvin (upper plot) and phases in degrees (bottom plot) observed at $40^{\circ} \mathrm{N}$ during 2002-2007; (b) the same as (a) but for the SABER semidiurnal oscillation (that is a superposition of all semidiurnal tides with zonal wavenumbers up to 4) for a geographic point $\left(40^{\circ} \mathrm{N}, 105^{\circ} \mathrm{W}\right)$.

altitude range $(80-100 \mathrm{~km})$ as that of the lidar. To facilitate the comparison with the phase plots of Fig. 1 from YETAL08 the horizontal axis changes from 00:00 to 18:00 LT. A careful comparison of lidar and SABER phases for the considered months indicates a high degree of similarity between both phase profiles. The vertical wavelength, calculated by a linear approximation, is marked at the bottom left side of each plot. The obtained wavelengths are similar to those mentioned in YETAL09, i.e. $\sim 38 \mathrm{~km}$ in winter, $\sim 92 \mathrm{~km}$ in summer and $\sim 50 \mathrm{~km}$ in fall.

The presented comparison between semidiurnal oscillations observed by SABER/TIMED and lidar temperature measurements provides clear evidence that there is no system-dependent vertical wavelength. It however points out that when the altitude distribution of the vertical phase gradient is variable the calculation of the vertical wavelength using observations only from an altitude range shorter than the wavelength itself could be rather misleading. (a)

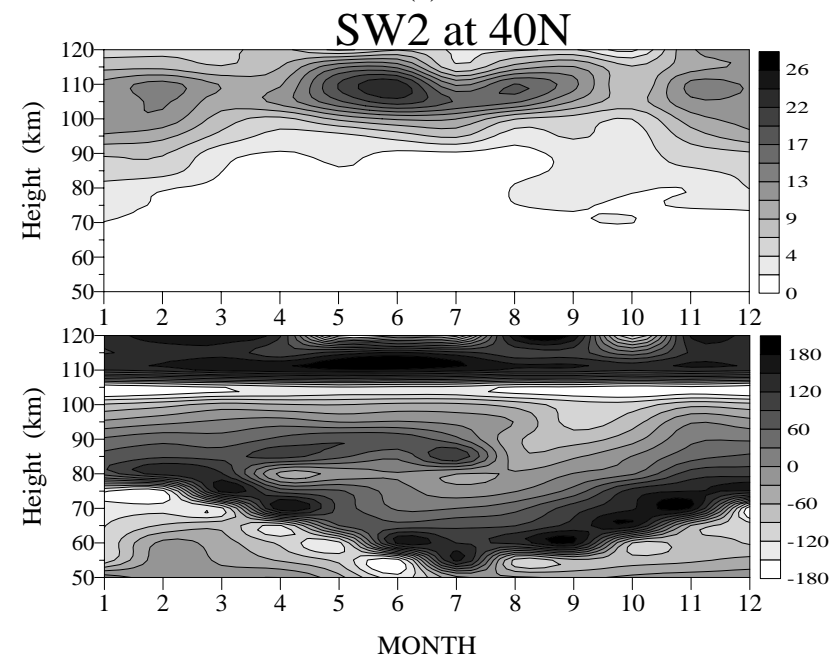

(b)

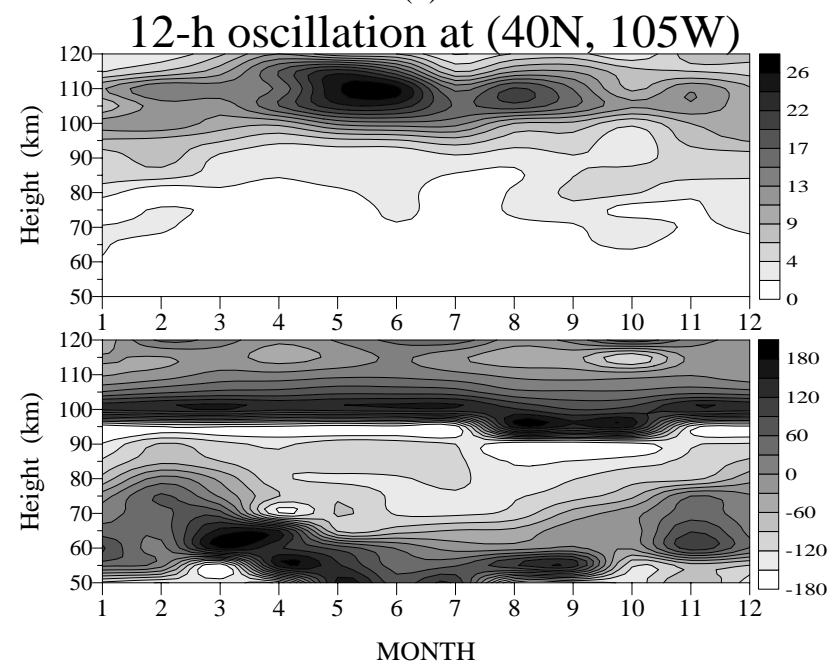

Fig. 3. (a) Average (2002-2007) vertical/seasonal structures of the SABER SW2 tide; (b) the same as (a) but for the SABER semidiurnal oscillation at a geographic point $\left(40^{\circ} \mathrm{N}, 105^{\circ} \mathrm{W}\right)$.

In PETAL09 has been mentioned also that the difference between the lidar semidiurnal tide observed over Fort Collins and the SABER tide at $40^{\circ} \mathrm{N}$ defines a different contribution of the Hough modes; while for the lidar semidiurnal tide the Hough modes with very long vertical wavelengths $(2,2)$ and $(2,3)$ are dominant in summer the SABER tide is composed by modes with significantly shorter wavelength as $(2,4)$ and $(2,5)$ modes. A Hough mode analysis of the SABER temperature SW2 tide would give answer to the above mentioned suggestion. A decomposition of the temperature SW2 tide is performed by using the tabulated associated Legendre polynomial expansion coefficients for the Hough functions given by Chapman and Lindzen (1970). Only the modes from $(2,2)$ to $(2,9)$ are included in the decomposition performed on the average (for 6 years) SABER temperature SW2 tide. 

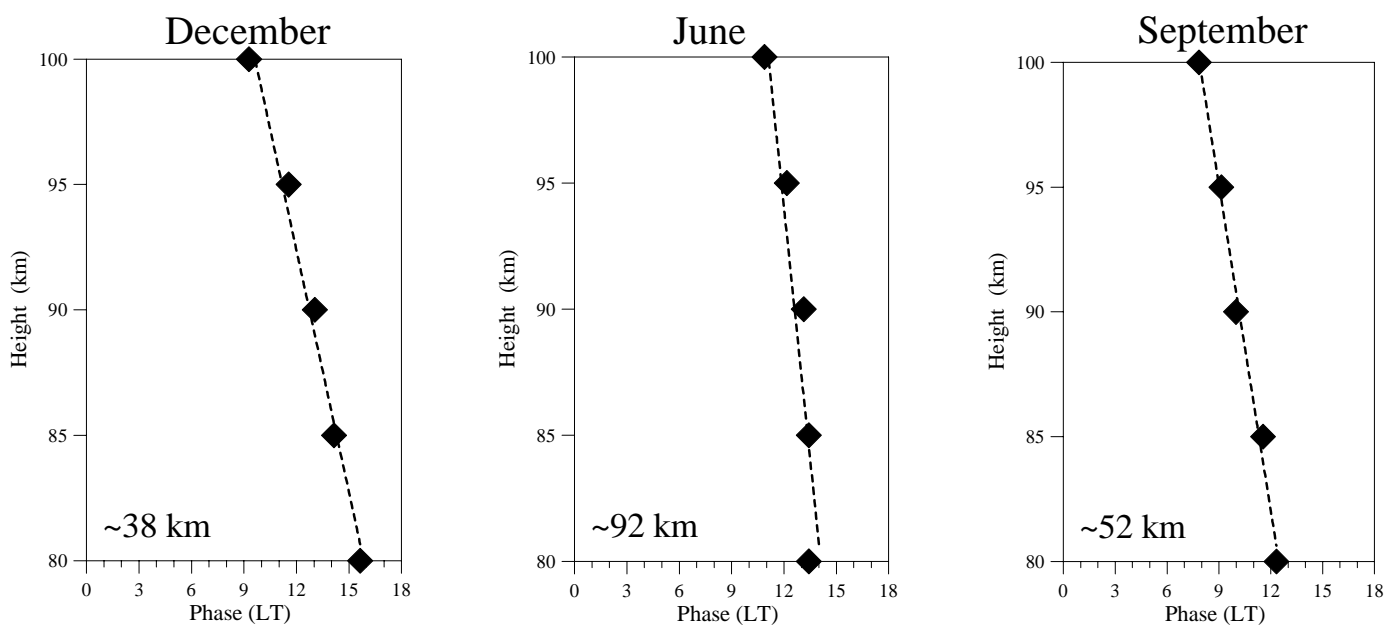

Fig. 4. Vertical phase profiles of the SABER semidiurnal oscillation at a geographic point $\left(40^{\circ} \mathrm{N}, 105^{\circ} \mathrm{W}\right)$ for the months: December (left plot), June (middle plot) and September (right plot).
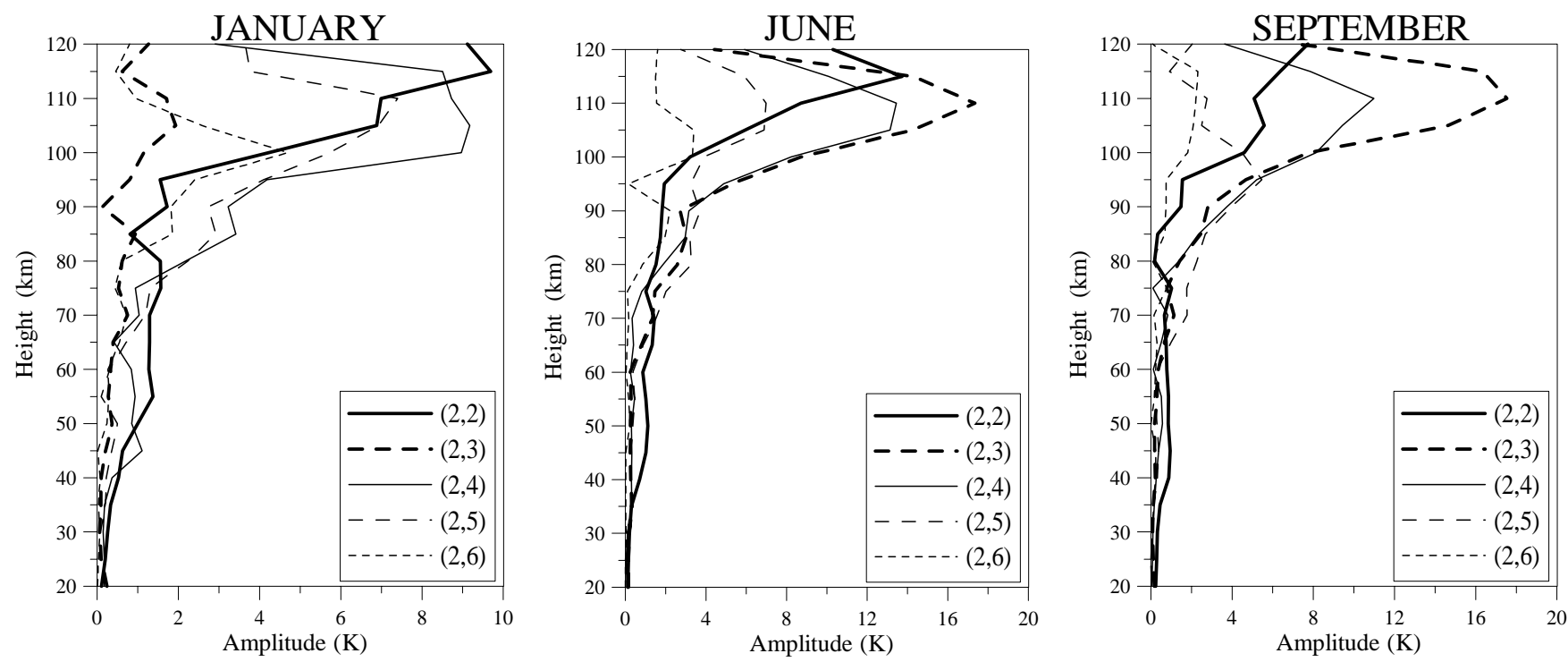

Fig. 5. The amplitude profiles of the Hough mode components for the SABER temperature SW2 tide obtained for January (left plot), June (middle plot) and September (right plot). The different Hough mode amplitudes are denoted by the following lines: $(2,2)-$ tick solid; $(2,3)$ - thick large dash; $(2,4)$ - tin solid, $(2,5)$ - thin large dash and $(2,6)$ - thin small dash.

The amplitudes of the Hough mode components of temperature for January (left plot), June (middle plot) and September (right plot) are shown in Fig. 5. The amplitude profiles are displayed for altitudes between 20 and $120 \mathrm{~km}$. The different Hough mode amplitudes are denoted by the following lines: $(2,2)$ - tick solid; $(2,3)$ - thick large dash; $(2,4)$ - tin solid, $(2,5)$ - thin large dash and $(2,6)$ - thin small dash. While in the altitude range $75-110 \mathrm{~km}$ the winter (January, left plot) SABER SW2 tide is composed mainly by $(2,4)$ and $(2,5)$ modes, in the altitude range $80-100 \mathrm{~km}$ besides them the $(2,6)$ mode contributes as well. The contribution of the above mentioned high modes explains the observed short wavelength, $\sim 35 \mathrm{~km}$, of the winter SABER SW2 tide. The summer (June, middle plot) SABER SW2 tide is composed mainly by $(2,3),(2,4)$ and $(2,5)$ modes in altitude range 70 $105 \mathrm{~km}$. The presence of $(2,3)$ mode in the composition of the SABER summer SW2 tide defines its larger, comparing with the winter one, vertical wavelength, $\sim 50-60 \mathrm{~km}$. It is worth noting that the $(2,2)$ is present in both seasons, however it amplifies above $\sim 100-105 \mathrm{~km}$ altitude. A careful inspection of the phase plots in Fig. 2a or Fig. 3a indicates that the regular phase structure showing upward propagation of the SW2 tide is visible only up to $\sim 105 \mathrm{~km}$ height. Most probably this is related to the fact that the $(2,2)$ mode 
becomes dominant mode above $\sim 110-115 \mathrm{~km}$. The autumn (September, right plot) SABER SW2 tide is composed by the same modes as the summer ones, but the contribution of the $(2,2)$ mode is significantly weaker. That is why the autumn SW2 vertical wavelength is slightly shorter than the summer one.

The above presented Hough mode analysis proves the suggestion made in PETAL09, that the modes with significantly shorter wavelengths as $(2,4),(2,5)$ and $(2,6)$ modes contribute to the composition of the SABER SW2 tide.

\section{Seasonal features of semidiurnal tide observed by MF and meteor radars in midlatitudes}

The second problem raised by METAL09 is related to the seasonal variability of the semidiurnal amplitude observed in the MLT neutral winds. This concern was provoked by the following two sentences mentioned in the Summary chapter of PETAL09: "For altitudes between 70 and $90 \mathrm{~km}$ besides the winter maximum an autumn (September in NH and March in SH) tidal amplification is evident as well. The September maximum detected at northern middle latitudes is well documented by radar studies." The first sentence is entirely applied to the seasonal behavior of the temperature SW2 tide. Similar seasonal course could be expected for the zonal and meridional wind SW2 tide and this was found by Burrage et al. (1995) using horizontal wind field from the High Resolution Doppler Imager (HRDI) on the Upper Atmosphere Research Satellite (UARS). McLandress et al. (1996) used the thermospheric winds $(90-110 \mathrm{~km})$ from the Wind Imaging Interferometer (WINDII) on UARS to delineate the structure of the SW2 wind tide from equator to lower middle latitudes $\left( \pm 35^{\circ}\right)$. The authors revealed that the SW2 wind tide maximizes in summer/early fall at altitude of $100 \mathrm{~km}$ and latitude of $35^{\circ} \mathrm{N}$. Similar results were obtained for the SABER SW2 tide in the lower thermosphere presented by PETAL09. We have to have in mind however that the seasonal behavior of temperature tidal component is not necessarily the same as the neutral wind ones. The reason behind it is the different latitudinal characteristic of the same Hough mode in temperature, zonal wind and meridional wind field.

The main argument in the METAL09 comment against the above mentioned two sentences in PETAL09 is based on the ground-based radar measurements and particularly MF radars situated at Saskatoon $\left(52^{\circ} \mathrm{N}\right)$ and Platteville $\left(40^{\circ} \mathrm{N}\right)$. The average (2002-2007) seasonal behavior of the semidiurnal tide observed in the zonal and meridional winds in the altitude range $73-97 \mathrm{~km}$ at both sites (Fig. 1 in METAL09) indicates a main maximum in September and secondary one in winter. First, the radar detected semidiurnal tide is not a migrating tide; it is a superposition of all semidiurnal tides. Second, it has been already shown that the September amplification is partly due to contribution of the nonmigrating tides (particularly in the temperature field). Third, the seasonal behavior of the semidiurnal tide obtained by "all-sky" meteor radar measurements is different from that obtained by MF radar: it reveals a main maximum in winter and secondary one in late summer/early fall. Jacobi et al. (2008) presented the mean winds and tides measured by meteor radar at Collm $\left(52^{\circ} \mathrm{N}\right)$ in altitude range $82-98 \mathrm{~km}$ during 2007. The authors show that while the semidiurnal zonal wind amplitude near altitude of $88-90 \mathrm{~km}$ reaches magnitude of 30$40 \mathrm{~m} / \mathrm{s}$ in January, it is not more than $20 \mathrm{~m} / \mathrm{s}$ in September. The semidiurnal tide defined by the meteor radar measurements at high latitudes demonstrates similar seasonal behavior, however both winter and September amplifications have different vertical structure. The tidal amplitude of the winter maximum increases with height while the September one maximizes near $87-88 \mathrm{~km}$. Riggin et al. (2003) investigated the September enhancement of the semidiurnal tide in high latitudes and found that the tidal amplification near $86-88 \mathrm{~km}$ height is due to refraction of the tide in the hemispheric wind circulation. Smith et al. (2007) suggested another reason for the September tidal enhancement related to the interference between migrating and nonmigrating tides. In this study we provided evidence that the September tidal amplification in the altitude range of $80-90 \mathrm{~km}$ is due to the superposition effect of all tides.

In order to support the seasonal variability of the semidiurnal tide obtained by MF radar measurements, i.e. the main September maximum, METAL09 used some modeling results, particularly those from Canadian Middle Atmosphere Model (CMAM) enlarged by the developed by Ren et al. (2008) Data Assimilation System (DAS). The comparison between the measured by Saskatoon MF radar and model semidiurnal tides for 2006 is sown in Fig. 2 of METAL09. While the measured semidiurnal characteristics are presented in the altitude range of $60-97 \mathrm{~km}$ strangely those of the model tide is shown only up to $88 \mathrm{~km}$ height. It is known that the upward extension of the standard CMAM is to $95 \mathrm{~km}$, while that of the extended CMAM - to $\sim 210 \mathrm{~km}$ (Du et al., 2007). Therefore, the model results should be shown at least up to $95 \mathrm{~km}$ height.

The seasonal features of the migrating and nonmigrating semidiurnal tides from the extended CMAM were reported by Du et al. (2007). The authors showed that at $95 \mathrm{~km}$ height and at $50^{\circ} \mathrm{N}$ the main maximum is the winter one reaching amplitudes of $35-40 \mathrm{~m} / \mathrm{s}$, while the September maximum is only $20-25 \mathrm{~m} / \mathrm{s}$. The maxima located at $50^{\circ} \mathrm{N} / \mathrm{S}$ for both wind components vary semiannually under solstice conditions, as observed by HRDI (Burrage et al., 1995). The vertical wavelength is larger than $40 \mathrm{~km}$.

One of the frequently used tidal model that can be freely downloaded from the web site: http://www.hao.ucar.edu/ modeling/gswm/gswm.html is the GSWM-02. This model includes some nonmigrating tidal sources and its description can be found in Hagan and Forbes (2003). Figure 6 shows the altitude-time cross sections of the 12-h tidal (superposition of 


\section{GSWM-02, Sum 12-h tides, $\left(51^{0} \mathrm{~N}, 105^{\circ} \mathrm{W}\right)$}
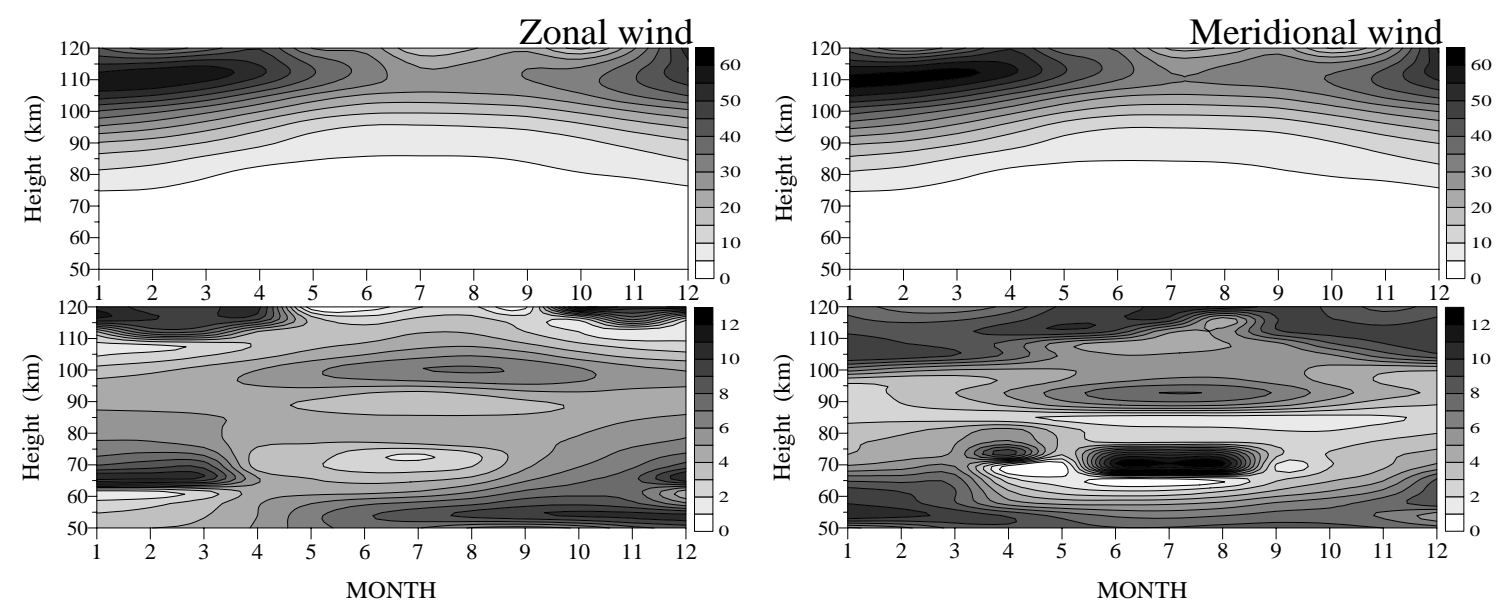

Fig. 6. Altitude-time cross sections of the GSWM- 02 semidiurnal tidal characteristics in zonal (left column of plots) and meridional (right column of plots) winds at latitude of $51^{\circ} \mathrm{N}$.

all 12-h tides with zonal wavenumbers between +6 and -6 ) characteristics in zonal (left column of plots) and meridional (right column of plots) winds for geographic point $\left(51^{\circ} \mathrm{N}\right.$, $105^{\circ} \mathrm{W}$ ), i.e. the point which is very close to Saskatoon $\left(52^{\circ} \mathrm{N}, 107^{\circ} \mathrm{W}\right)$. This model also indicates that the winter maximum is the main one, while the late summer/early fall maximum is almost absent. The vertical wavelength in winter is $\sim 45 \mathrm{~km}$, while it is difficult to be determined in summer.

The SW2 tidal features from the GSWM-02 (or GSWM00) are supported by HRDI wind measurements (Burrage et al., 1995), by SABER temperature SW2 tide (PETAL09) and by the all-sky meteor radars located at middle and high latitudes. We note however that the radar semidiurnal tide is not a migrating tide; it is a superposition of semidiurnal tides, i.e. semidiurnal oscillation. However, as the migrating tide is a dominant one the seasonal course of the semidiurnal oscillation to a large extent is defined by it.

The problem for the difference between the MF and meteor radar wind measurements has been known for long time. Many comparative studies with simultaneous measurements at the same location were performed without offering any clear idea able to explain the observed differences. Recently Manson et al. (2004) and Jacobi et al. (2009) by comparing the wind measurements from the co-located MF and all-sky system meteor radars found that usually the absolute values of winds measured by MF radar are smaller than those measured by meteor radar. While the differences are small at altitudes of 82-85 they increase with height up to a factor of 2 or more (Jacobi et al., 2009). It was found also that the difference significantly increases during winter. Jacobi et al. (2009) suggested that the seasonal dependence may indicate an indirect influence of gravity waves which, according to most climatologies, show more activity in winter than in summer above $90 \mathrm{~km}$.

Another possible reason for the seasonal dependence of the difference between the MF and meteor radar wind measurements could be the well known event in the lower ionosphere (D-region), originally seen in radio wave absorption data and called "winter anomaly". This event is related to a mean excess of the HF and MF radio wave absorption at fix zenith angle in winter than that in summer (Lauter et al., 1969). In the 1970s there were organized two dedicated rocket campaigns to study this phenomenon, in the United States from two latitudes (Aikin et al., 1977) and in El Arenosillo, Spain (Offermann, 1979). The conclusion was that nitric oxide (NO) on groups of days was enhanced in the mesosphere; this in turn has been attributed to the more variable downward transport in mid-latitude winter. The NO, because of its low ionization threshold - is a key constituent for the formation of the daytime D-region. As a combined effect of global circulation and photolysis, there is more NO in the less illuminated winter hemisphere. It is precisely near the mesopause where NO being ionized by Lyman- $\alpha$ radiation, and this way constitutes the most important ionization source (Friedrich and Rapp, 2009). The analysis of the SNOE satellite data presented by Barth et al. (2003) showed also a dayto-day variability of typically a factor 2 at the equator and a factor of 3 in the auroral zone. The electron density profiles in the D-region built on the basis of multifrequency absorption measurements also indicated a significant enhancement of the electron concentration in winter above $85-90 \mathrm{~km}$ height (Pancheva and Mukhtarov, 1996). Mukhtarov (1995) found also that the phenomenon "winter anomaly" is valid for the ionosphere E-region as well. 
As the operational frequency of the MF radars is usually $2-3 \mathrm{MHz}$ their measurements have to be affected by significantly increased electron density above $85-90 \mathrm{~km}$ height in winter. This means that the radiowave reflection height, respectively the altitude range for which the neutral wind data are allocated, should be changed considerably during winter in comparison with other seasons. The absorption measurements revealed that the electron density in the mesopause region can increase at least an order of magnitude during stratospheric warmings (Lauter et al., 1969). Such events can be used for simultaneous co-located MF and meteor radar measurements in order to asses a possible winter anomaly effect on the MF radar data.

\section{Summary}

In the present reply we focused on three topics:

- By a detailed comparison between the seasonal characteristics of the SABER/TIMED semidiurnal oscillation, composed of all semidiurnal tides with zonal wavenumber up to 4 , for a geographic point $\left(40^{\circ} \mathrm{N}, 105^{\circ} \mathrm{W}\right)$ and the Na lidar observations over Fort Collins, Colorado $\left(41^{\circ} \mathrm{N}, 105^{\circ} \mathrm{W}\right)$ it was provided clear evidence that there is no system-dependent vertical wavelength and that the September amplification in the altitude range of $80-90 \mathrm{~km}$ is affected by the nonmigrating tides. We pointed out also that when the altitude distribution of the vertical phase gradient is variable the calculation of the vertical wavelength using observations only from an altitude range shorter than the wavelength itself could be rather misleading. This is a significant weak point of the ground-based radar and lidar measurements.

- The performed Hough mode analysis revealed that the modes with significantly shorter wavelengths, as $(2,4)$, $(2,5)$ modes and in winter $(2,6)$ mode as well, contribute to the composition of the SABER SW2 tide. While the $(2,3)$ mode contributes to summer and fall SABER SW2 tide, the $(2,2)$ mode becomes dominant only above $\sim 110 \mathrm{~km}$ for solstice SW2 tide.

- The third topic was related to the seasonal dependence of the difference between the MF and meteor radar wind measurements. The presented by METAL09 evidence for a main September maximum and secondary winter one of the MLT semidiurnal tide observed mainly by MF radars is not supported by all-sky system meteor radar measurements. The seasonal behavior of the semidiurnal wind tide detected by meteor radars is dominated by a main winter and secondary late summer/early fall maxima. The extended CMAM and GSWM-02 support the meteor radar results. It has been suggested that the seasonal dependence of the difference between the MF and meteor radar wind mea- surements can be affected by the phenomenon "winter anomaly" in the lower ionosphere (D- and E-region).

Acknowledgements. We are grateful to the SABER team (http: //saber.gats-inc.com) and M. Hagan (http://www.hao.ucar.edu/ modeling/gswm/gswm.html) for the access to the SABER temperature measurements and GSWM-02 data respectively.

Topical Editor C. Jacobi thanks one anonymous referee for her/his help in evaluating this paper.

\section{References}

Aikin, A. C., Goldberg, R. A., Jones, W., and Kane, J. A.: Observations of the mid-latitude lower ionosphere in winter, J. Geophys. Res., 82(13), 1869-1875, 1977.

Barth, C. A., Mankoff, K. D., Bailey, S. M., and Solomon, S. C.: Global observations of nitric oxide in the thermosphere, J. Geophys Res, 108(A1), 1027, doi:10.1029/2002JA009458, 2003.

Burrage, M. D., Wu, D. L., Skinner, W. R., Ortland, D. A., and Hays, P. B.: Latitude and seasonal dependence of the semidiurnal tide observed by the high-resolution Doppler imager, J. Geophys. Res., 100(D6), 11313-11321, 1995.

Chapman, S. and Lindzen, R. S.: Atmospheric Tides: Thermal and Gravitational, 200 pp., Gordon and Breach, New York, 1970.

Du, J., Ward, W. E., Oberheide, J., Nakamura, T., and Tsuda, T.: Semidiurnal tides from the extended Canadian Middle Atmosphere Model (CMAM) and comparisons with TIMED Doppler interferometer (TIDI) and meteor radar observations, J. Atmos. Solar-Terr. Phys., 69, 2159-2202, 2007.

Friedrich, M. and Rapp, M.: News from the lower ionosphere: A review of recent development, Surv. Geophys., 30, 525-559, 2009.

Hagan, M. E. and Forbes, J. M.: Migrating and nonmigrating semidiurnal tides in the upper atmosphere excited by tropospheric latent heat release, J. Geophys. Res., 108(A2), 1062, doi:10.1029/2002JA009466, 2003.

Jacobi, C., Stober, G., and Hoffmann, P.: Mean winds and tides over Collm $\left(51.3^{\circ} \mathrm{N}, 13^{\circ} \mathrm{E}\right)$ as measured with meteor radar and the LF D1 method in 2007, Rep. Inst. Meteorol. Univ. Leipzig, 42, 141-153, 2008.

Jacobi, C., Arras, C., Kuerschner, D., Singer, W., Hoffmann, P., and Keuer, D.: Comparison of mesopause region meteor radar winds, medium frequency radar winds and low frequency drifts over Germany, Adv. Space Res., 43, 247-252, 2009.

Lauter, E., Sprenger, K., and Entzian, G.: The lower ionosphere in winter, in: Stratospheric circulation, Acad. Press, 1969.

Manson, A. H., Meek, C. E., Hall, C.M., Nozawa, S., Mitchell, N.J., Pancheva, D., Singer, W., and Hoffmann, P.: Mesopause dynamics from the scandinavian triangle of radars within the PSMOSDATAR Project, Ann. Geophys., 22, 367-386, 2004, http://www.ann-geophys.net/22/367/2004/.

McLandress, C., Shepherd, G. G., and Solheim, B. H.: Satellite observations of thermospheric tides: Results from the Wind Imaging Interferometer on UARS, J. Geophys. Res., 101(D2), 40934114, doi:10.1029/95JD03359, 1996.

Mukhtarov, P.: Diurnal and seasonal changes of the maximum electron density in the ionsophere E-region, Bulg. Geophys. J., XXI(2), 1995 (in Bulgarian).

Mukhtarov, P., Pancheva, D., and Andonov, B.: Global Structure, seasonal and interannual variability of the migrating 
diurnal tide seen in the SABER/TIMED temperatures between 20 and $120 \mathrm{~km}$, J. Geophys. Res., 114, A02309, doi:10.1029/2008JA013759, 2009.

Offermann, D.: A study of D-region winter anomaly in western Europe, 1975/76, J. Atmos. Terr. Phys. 41, 1-13, 1979.

Pancheva, D. and Mukhtarov, P.: Modeling of the electron density height-profiles in the midlatitude ionospheric D-region, Ann. di Geofisica, xxxix(4), 819-824, 1996.

Pancheva, D., Mitchell, N. J., Hagan, M. E., et al.: Global-scale tidal structure in the mesosphere \& lower thermosphere during the PSMOS campaign summer-99 and comparison with the Global Scale Wave Model, J. Atmos. Solar-Terr. Phys., 64, 10111035, 2002.

Pancheva, D., Mukhtarov, P., and Andonov, B.: Global structure, seasonal and interannual variability of the migrating semidiurnal tide seen in the SABER/TIMED temperatures (2002-2007), Ann. Geophys., 27, 687-703, 2009a, http://www.ann-geophys.net/27/687/2009/.

Pancheva, D., Mukhtarov, P., Andonov, B., Mitchell, N. J., and Forbes, J. M.: Planetary waves observed by TIMED/SABER in coupling the stratosphere-mesosphere-lower thermosphere during the winter of 2003/2004: Part 1, Comparison with the UKMO temperature results, J. Atmos. Solar-Terr. Phys., 71(1), 61-74, 2009b.

Pancheva, D., Mukhtarov, P., and Andonov, B.: Nonmigrating tidal activity related to the sudden stratospheric warming in the Arctic winter of 2003/2004, Ann. Geophys., 27, 975-987, 2009c, http://www.ann-geophys.net/27/975/2009/.

Ren, S., Polavarapu, S. M., and Shepherd, T. G.: Vertical propagation of information in a middle atmosphere data assimilation system by gravity-wave drag feedbacks, Geophys. Res. Lett., 35, L06804, doi:10.1029/2007GL032699, 2008.
Riggin, D. M., Meyer, C. K., Fritts, D. C., et al.: MF radar observations of seasonal variability of semidiurnal motions in the mesosphere at high northern and southern latitudes, J. Atmos. Solar-Terr. Phys., 65, 483-493, 2003.

She, C. Y.: Initial full-diurnal-cycle mesopause region lidar observations: Diurnal-means and tidal perturbations of temperature and winds over Fort Collins, CO (41N, 105W), PSMOS 2002, J. Atmos. Solar Terr. Phys., 66, 663-674, 2004.

She, C. Y., Chen, S., Williams, B. P., et al.: Tides in the mesopause region over Fort Collins, $\mathrm{CO}\left(41^{\circ} \mathrm{N}, 105^{\circ} \mathrm{W}\right)$ based on lidar temperature observations covering full diurnal cycles, J. Geophys. Res., 107(D18), 4350, doi:10.1029/2001JD001189, 2002.

She, C. Y., Sherman, J., Yuan, T., et al.: The first 80-hour continuous lidar campaign for simultaneous observation of mesopause region temperature and wind, Geophys. Res. Lett., 30(6), 1319, doi:10.1029/2002GL016412, 2003.

She, C. Y., Li, T., Collins, R. L., et al.: Tidal perturbations and variability in mesopause region over Fort Collins, $\mathrm{CO}\left(41^{\circ} \mathrm{N}, 105^{\circ} \mathrm{W}\right)$ : Continuous multi-day temperature and wind lidar observations, Geophys. Res. Lett., 31, L24111, doi:10.1029/2004GL021165, 2004.

Zhang, X., Forbes, J. M., Hagan, M. E., Russell III, J. M., Palo, S. E., Mertens, C. J., and Mlynczak, M. G.: Monthly tidal temperatures 20-120 km from TIMED/SABER, J. Geophys. Res., 111, A10S08, doi:10.1029/2005JA011504, 2006.

Yuan, T., Schmidt, H., She, C. Y., Krueger, D. A., and Reising, S.: Seasonal variations of semidiurnal tidal perturbations in mesopause region temperature and zonal and meridional winds above Fort Collins, Colorado $\left(41^{\circ} \mathrm{N}, 105^{\circ} \mathrm{W}\right)$, J. Geophys. Res., 113, D20103, doi:10.1029/2007JD009687, 2008. 